\title{
Polyarylates Containing Sulfone Ether Linkages
}

\author{
Sheng-Huei HSIAO and Jiun-Hsiang CHIOU \\ Department of Chemical Engineering, Tatung University, \\ 40 Chungshan North Road, Section 3, Taipei, Taiwan, Republic of China
}

(Received September 11, 2000; Accepted October 25, 2000)

\begin{abstract}
A series of polyarylates containing sulfone or both of ether and sulfone groups were synthesized from diacid chlorides such as 4,4'-sulfonyldibenzoyl chloride (SDBC), 4,4'-[sulfonylbis(1,4-phenylene)dioxy]dibenzoyl chloride (SODBC), and 4,4'-[sulfonylbis(2,6-dimethyl-1,4-phenylene)dioxy]dibenzoyl chloride (4MeSODBC) with various bisphenols by the interfacial polycondensation technique. Moderate to high molecular weight polyarylates with inherent viscosity up to $1.22 \mathrm{dL} \mathrm{g}^{-1}$ were obtained. Most of them were soluble in various organic solvents and afforded transparent, flexible, and tough films by solution casting. Two polyarylates based on SDBC exhibited a moderate level of crystallinity and poor solubility; however, the introduction of ether linkages into the polymer backbone caused a decreased crystallinity and an enhanced solubility. The incorporation of ether groups in the sulfonyl polyarylate main chain led to a decreased glass transition temperature $\left(T_{\mathrm{g}}\right)$ or softening temperature $\left(T_{\mathrm{s}}\right)$. The methyl-substituted poly(ether-sulfonearylate)s from $4 \mathrm{MeSODBC}$ reveal higher $T_{\mathrm{g}}$ or $T_{\mathrm{s}}$ but lower decomposition temperatures than the corresponding nonsubstituted analogs from SODBC.
\end{abstract}

KEY WORDS Polyarylates / Ether-Sulfone-Diacid Chlorides / Interfacial Polycondensation /

Polyarylates are well accepted as high performance engineering thermoplastics which have found application in a variety of areas. ${ }^{1,2}$ However, the high melting or softening temperatures and limited solubility in organic solvents of most polyarylates make their processing into articles difficult unless flexible spacers are included in the backbone, thereby lowering the thermal stability. One of the successful approaches to increase solubility and processability without much sacrifice of thermal stability is the introduction of polar and kinked linkages such as sulfone and ether groups into the polymer backbone. In previous papers ${ }^{3-7}$ we have shown that multi-ring dianhydrides, diacids and diamines containing diaryloxy groups together with sulfonyl group are able to give rise to aromatic polyamides and polyimides with increased solubility as compared to rigid analogues, while retaining moderately high $T_{\mathrm{g}}$ and thermal stability. The present investigation deals with the synthesis and basic characterization of poly(ether-sulfonearylate)s prepared from diacid chlorides SODBC and $4 \mathrm{MeSODBC}$ with various bisphenols, with the aim being to correlate their structural features with solubility, crystallinity, $T_{\mathrm{g}}$ and thermal stability. For comparison, related sulfonyl polyarylates without ether linkages were also prepared and characterized.

\section{EXPERIMENTAL}

\section{Materials}

The commercial available biphenols that included 4,4'-biphenol (1a) (TCI), 3,3',5,5'-tetramethyl-4,4'biphenol (1b) (Mitsui Petrochemical Ind.), 2,2-bis(4hydroxyphenyl)propane (bisphenol A; 1c) (Wako), 1,1-bis(4-hydroxyphenyl)-1-phenylethane (1d) (Mitsui Petrochemical Ind.), 2,2-bis(4-hydroxyphenyl)hexafluoropropane (bisphenol AF; 1e) (Kriskev), $\quad \alpha, \alpha^{\prime}$-bis (4hydroxyphenyl)-1,4-diisopropylbenzene (1f) (Mitsui Petrochemical Ind.), $\alpha, \alpha^{\prime}$-bis ( 4-hydroxyphenyl )-1,3diisopropylbenzene (1g) (Mitsui Petrochemical Ind.),
4,4' - (octahydro-4,7-methano-5H-inden-5-ylidene) bisphenol (1h) (Acros) and 9,9-bis(4-hydroxyphenyl)fluorene (1i) (TCI) were used without further purification. The phase-transfer agent, triethylbenzylammonium chloride (TEBAC) (TCI), was used as received. As reported previously, ${ }^{3}$ 4,4'-[sulfonylbis(1,4-phenylene)dioxy]dibenzoic acid $\left(\mathrm{mp} 291-292^{\circ} \mathrm{C}\right.$ ) and $4,4^{\prime}$-[sulfonylbis (2,6-dimethyl-1,4-phenylene)dioxy]dibenzoic acid (mp $312-315^{\circ} \mathrm{C}$ ) were synthesized in high purity and high yields via two main steps from commercially available reagents. The diacyl chloride monomers, 4,4' sulfonyldibenzoyl chloride (SDBC) $\left(\mathrm{mp} 160-161^{\circ} \mathrm{C}\right.$; lit. $^{8}$ $\left.164^{\circ} \mathrm{C}\right), \quad 4,4^{\prime}$-[sulfonylbis (1,4-phenylene)dioxy]dibenzoyl chloride (SODBC) $\left(\mathrm{mp} 183-184^{\circ} \mathrm{C}\right.$; lit. $\left..^{9,10} 183-185^{\circ} \mathrm{C}\right)$ and 4,4'-[sulfonylbis(2,6-dimethyl-1,4-phenylene)dioxy] dibenzoyl chloride (4MeSODBC) $\left(\mathrm{mp} 190-191^{\circ} \mathrm{C}\right)$, were prepared by chlorinating the precursor dicarboxylic acid with thionyl chloride in the presence of trace amount of $N, N$-dimethylformamide. Dichloromethane was purified by distillation. All other solvents were obtained commercially and used as received.

\section{Polymer Synthesis and Film Preparation}

The interfacial polycondensation technique was used to prepare the polyarylates in this research. A typical procedure for the synthesis of polyarylate $\mathbf{4 b}$ is given below. A solution of $4 \mathrm{MeSODBC}(0.5834 \mathrm{~g} ; 1 \mathrm{mmol})$ in dichloromethane $(10 \mathrm{~mL})$ was added all at once to a solu-

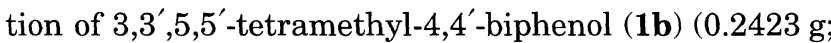
$1 \mathrm{mmol}$ ) and $0.04 \mathrm{~g}$ TEBAC in $10 \mathrm{~mL}$ of $1 \mathrm{M}$ aqueous sodium hydroxide. The reaction mixture was stirred vigorously at room temperature for $1 \mathrm{~h}$. The mixture was poured into $350 \mathrm{~mL}$ of boiling water to remove dichloromethane. The precipitated polymer was collected by filtration, washed with water thoroughly, and dried. The yield of polymer $\mathbf{4 b}$ was quantitative, and the inherent viscosity was $1.00 \mathrm{dL} \mathrm{g}^{-1}$ as measured at a concentration of $0.5 \mathrm{~g} \mathrm{dL}^{-1}$ in 1,1,2,2-tetrachloroethane/phenol ( $40 / 60$ by weight) at $30^{\circ} \mathrm{C}$. The IR spectrum (film) 
showed characteristic absorptions at $1733(\mathrm{C}=\mathrm{O}$ str. $)$, 1321, 1159 ( $\mathrm{S}=\mathrm{O}$ str.), $1267 \mathrm{~cm}^{-1}(\mathrm{C}-\mathrm{O})$. Anal. Calcd for $\left(\mathrm{C}_{46} \mathrm{H}_{40} \mathrm{SO}_{8}\right)_{n}(752.88)_{n}$ : C, 73.38\%; H, 5.35\%. Found: C, $72.88 \%$; H, $5.40 \%$.

The polymer thin film was cast from the solution of polyarylate $\mathbf{4 b}$ in 1,1,2,2-tetrachloroethane (TCE) in a clean glass culture dish. The wet film was placed in a $90^{\circ} \mathrm{C}$ oven for $12 \mathrm{~h}$ to remove the solvent slowly. The semidried film was further dried under vacuum at $150^{\circ} \mathrm{C}$ for $6 \mathrm{~h}$. The thickness of the film was about $60 \mu \mathrm{m}$. All the other polyarylates were prepared by a similar procedure described the above.

\section{Measurements}

Inherent viscosities $\left(\eta_{\text {inh }}\right)$ of the polyarylates were measured with a Cannon-Fenske viscometer from a polymer solution at $0.5 \mathrm{~g} \mathrm{dL}^{-1}$ concentration in $1,1,2,2$ tetrachloroethane/phenol (40/60 by weight) at $30^{\circ} \mathrm{C}$. Molecular weight data for some of the polyarylates were determined by gel permeation chromatography (GPC) in tetrahydrofuran (THF) based on polystyrene standards on a Waters apparatus. The infrared spectra were recorded on a Horiba Fourier Transform Infrared Spectrometer FT-720. Wide-angle X-Ray diffraction measurements were performed at room temperature on a Siemens Kristalloflex D 5000 X-Ray diffractometer, operating in the $2 \theta$ range of $5-45^{\circ}$ at the scan rate of $3^{\circ}$ $\min ^{-1}$ using Ni-filtered copper $K_{\alpha}$ radiation $(\lambda=1.5418$ $\AA$, operating at $40 \mathrm{kV}$ and $20 \mathrm{~mA}$ ). Differential scanning calorimetry (DSC) was performed on a Perkin-Elmer DSC 7 in flowing nitrogen with a heating rate of $20^{\circ} \mathrm{C}$ $\min ^{-1}$. Glass transition temperatures $\left(T_{\mathrm{g}}\right)$ were read at the middle of the baseline shift on the second DSC heating trace after quenching the sample from $400^{\circ} \mathrm{C}$ at a programmed rate of $-200^{\circ} \mathrm{C} \mathrm{min}^{-1}$. Thermomechanical analysis (TMA) experiments were performed on a Perkin -Elmer TMA 7 at a heating rate $10^{\circ} \mathrm{C} \min ^{-1}$ with a loaded penetration probe under an applied constant load of $10 \mathrm{mN}$. The film samples were preheated at $250^{\circ} \mathrm{C}$ for 30 min prior to scan. The softening temperatures $\left(T_{\mathrm{s}}\right)$ were taken as the intersection of the extrapolation of the baseline with the extrapolation of inflection on the TMA traces. Thermogravimetric analysis (TGA) was conducted with a TA Instruments TGA 2050 Thermogravimetric Analyzer. Experiments were carried out on 9-11 mg samples heated in flowing nitrogen or air $\left(100 \mathrm{~cm}^{3}\right.$ $\min ^{-1}$ ) at a scan rate of $20^{\circ} \mathrm{C} \mathrm{min}^{-1}$. The measurements were taken after a $300^{\circ} \mathrm{C} / 10$ min drying step. An Instron universal tester model 1130 with a $5 \mathrm{~kg}$ load cell was used to measure the tensile properties of the solution cast films using a crosshead gauge of $2 \mathrm{~cm}$ and a crosshead speed of $5 \mathrm{~mm} \mathrm{~min}^{-1}$. Measurements were performed at room temperature with film specimens (5 $\mathrm{mm}$ wide, $60 \mathrm{~mm}$ long, and approximately $60 \mu \mathrm{m}$ thick). An average of at least five individual determinations was used.

\section{RESULTS AND DISCUSSION}

\section{Polymer Synthesis}

Polyarylates have been prepared conveniently by the phase-transfer catalyzed polycondensation of aromatic diacid chlorides with bisphenols. ${ }^{11-13}$ The polycondensa-

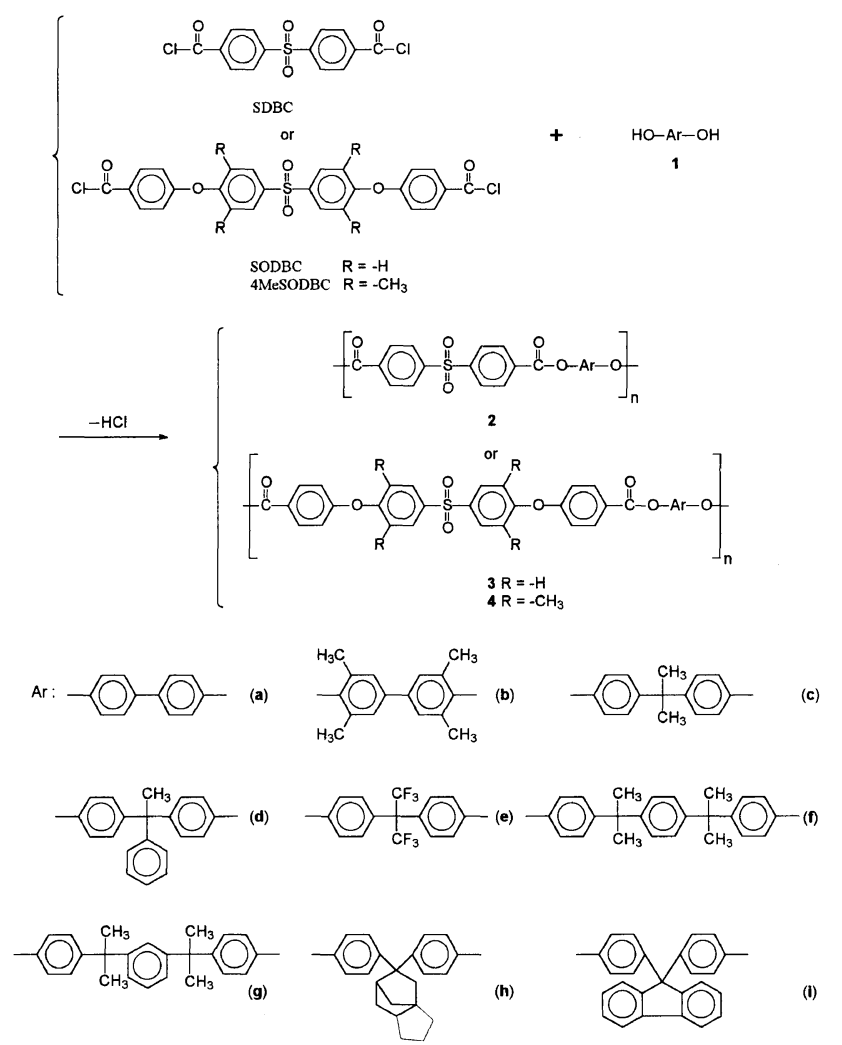

Scheme 1. Synthesis of sulfonyl polyarylates.

tions of bisphenols $\mathbf{1 a - 1 i}$ with diacid chlorides SDBC, SODBC, and 4MeSODBC leading to sulfone-containing or both ether and sulfone containing polyarylates were carried out in dichloromethane-aqueous sodium hydroxide system using TEBAC as a phase transfer catalyst, which is known to be a very effective catalyst for producing high molecular weight polyarylates. ${ }^{14-16}$ The molecular structures and codes of all the monomers and polymers are shown in Scheme 1, and the results of polycondensation are summarized in Table I. Polymer precipitation occurred during the polycondensation reactions of $4,4^{\prime}$-biphenol (1a) with any one of the three diacid chlorides due to insolubility of the resulting polyarylates. Unexpectedly, polymer $2 \mathbf{f}$ also precipitated out from the reaction system during the reaction. Insolubility of polymer $2 \mathbf{f}$ may be caused by its high level of crystallinity, as evidenced by X-Ray diffraction and DSC analysis discussed subsequently. All the polymers that precipitated during the polycondensation reaction could not be dissolved in suitable organic solvents for film casting. All other polyarylates were obtained with sufficient molecular weights for the casting of tough and flexible films. The cast films of the polyarylates $(\mathbf{2 b}, \mathbf{3 b}$, and 4b) derived from $3,3^{\prime}, 5,5^{\prime}$-tetramethyl-4,4'-biphenol (1b) appeared pale yellow in color, possibly due to bathochromic shifts caused by the methyl auxochromes. All the other films are transparent and colorless. The lower inherent viscosities of most polyarylates derived from SODBC, compared to those derived from SDBC and $4 \mathrm{MeSODBC}$, may be attributed in part to their more flexible molecular structures. In interpreting the viscosity behavior, one must bear in mind that the inherent viscosity of a flexible polymer is much lower than that of 
Table I. Synthesis and film quality of sulfonyl polyarylates

\begin{tabular}{|c|c|c|c|c|c|c|}
\hline \multirow{3}{*}{ Diacyl Chloride } & \multirow{3}{*}{ Bisphenol } & \multicolumn{5}{|c|}{ Polymer } \\
\hline & & \multirow{2}{*}{ Code } & \multirow{2}{*}{$\frac{\eta_{\text {inh }^{a}}}{d L g^{-1}}$} & \multirow{2}{*}{$\frac{M_{\mathrm{p}}^{\mathrm{b}}}{\mathrm{kg} \mathrm{mol}^{-1}}$} & \multirow{2}{*}{$\operatorname{Remarks}^{\mathrm{c}}$} & \multirow{2}{*}{ Film Quality $^{\mathrm{d}}$} \\
\hline & & & & & & \\
\hline \multirow[t]{9}{*}{ SDBC } & 1a & $2 \mathbf{a}$ & $-\mathrm{e}$ & & $P$ & -e \\
\hline & $1 b$ & $2 \mathrm{~b}$ & 1.00 & & $\mathrm{~S}$ & Flexible \\
\hline & $1 \mathrm{c}$ & $2 c$ & 0.95 & & $\mathrm{~S}$ & Flexible \\
\hline & 1d & $2 d$ & 1.07 & 155 & $\mathrm{~S}$ & Flexible \\
\hline & $1 e$ & $2 \mathbf{e}$ & 0.69 & & $\mathrm{~S}$ & Flexible \\
\hline & If & $2 f$ & 0.25 & & $P$ & - \\
\hline & $1 \mathrm{~g}$ & $2 \mathrm{~g}$ & 0.79 & & $\mathrm{~S}$ & Flexible \\
\hline & $1 \mathrm{~h}$ & $\mathbf{2 h}$ & 0.70 & 112 & $\mathrm{E}$ & Flexible \\
\hline & $1 \mathrm{i}$ & $2 \mathbf{2 i}$ & 0.60 & 95 & $\mathrm{E}$ & Flexible \\
\hline \multirow[t]{9}{*}{ SODBC } & $1 a$ & $\mathbf{3 a}$ & 0.21 & & $\mathrm{P}$ & - \\
\hline & $1 b$ & $\mathbf{3 b}$ & 0.63 & & $\mathrm{~S}$ & Flexible \\
\hline & $1 c$ & $3 \mathbf{c}$ & 0.45 & & $\mathrm{~S}$ & Flexible \\
\hline & 1d & 3d & 0.68 & 166 & $\mathrm{~S}$ & Flexible \\
\hline & $1 \mathbf{e}$ & $\mathbf{3 e}$ & 0.31 & & $\mathrm{~S}$ & Flexible \\
\hline & If & $3 f$ & 0.56 & & $\mathrm{E}$ & Flexible \\
\hline & $1 \mathrm{~g}$ & $3 \mathbf{g}$ & 0.58 & 183 & $\mathrm{E}$ & Flexible \\
\hline & $1 \mathrm{~h}$ & $\mathbf{3 h}$ & 0.32 & 138 & $\mathrm{E}$ & Flexible \\
\hline & $1 i$ & $3 \mathbf{i}$ & 0.62 & 189 & $\mathrm{E}$ & Flexible \\
\hline \multirow[t]{9}{*}{ 4MeSODBC } & $1 \mathbf{a}$ & $4 a$ & 0.22 & & $\mathrm{P}$ & - \\
\hline & $1 \mathbf{b}$ & $4 b$ & 1.00 & 256 & $\mathrm{~S}$ & Flexible \\
\hline & $1 \mathrm{c}$ & $\mathbf{4 c}$ & 0.58 & 197 & $\mathrm{~S}$ & Flexible \\
\hline & 1d & 4d & 1.21 & 247 & $\mathrm{~S}$ & Flexible \\
\hline & $1 \mathrm{e}$ & $\mathbf{4 e}$ & 1.22 & 236 & $\mathrm{~S}$ & Flexible \\
\hline & If & $\mathbf{4 f}$ & 0.89 & 220 & $\mathrm{~S}$ & Flexible \\
\hline & $1 \mathrm{~g}$ & $4 \mathrm{~g}$ & 0.74 & 273 & $\mathrm{~S}$ & Flexible \\
\hline & $1 \mathrm{~h}$ & $4 \mathrm{~h}$ & 1.09 & 292 & $\mathrm{E}$ & Flexible \\
\hline & $\mathbf{1 i}$ & $4 \mathbf{i}$ & 1.05 & 324 & $\mathrm{E}$ & Flexible \\
\hline
\end{tabular}

\footnotetext{
${ }^{a}$ Measured at a concentration of $0.5 \mathrm{~g} \mathrm{dL}^{-1}$ in 1,1,2,2-tetrachloroethane/phenol (40:60 by weight) at $30{ }^{\circ} \mathrm{C} .{ }^{\mathrm{b}}$ Molecular weights at the peaks of the chromatograms (GPC) relative to polystyrene standards. ${ }^{\mathrm{c}}$ Appearance of the polymerization: $\mathrm{P}$, polymer precipitation occurred during the reaction; E: viscous emulsion; S, homogeneous organic solution (well-defined two phases). " ${ }^{\mathrm{d}}$ Films were cast by slow evaporation of the polymer solutions in 1,1,2,2-tetrachloroethane. The films from polymers $\mathbf{2 b}, \mathbf{3 b}$, and $\mathbf{4 b}$ are pale yellow in color, and the other films are colorless. ${ }^{e}$ Insoluble.
}

a rigid one of the same molecular weight. This could be evidenced by GPC analysis. For example, polymer $\mathbf{3 h}$ had a lower inherent viscosity of $0.32 \mathrm{dL} \mathrm{g}^{-1}$ whereas showed a higher $M_{\mathrm{p}}$ value $\left(138 \mathrm{~kg} \mathrm{~mol}^{-1}\right.$ ) than that (112 $\mathrm{kg} \mathrm{mol}^{-1}$ ) of $\mathbf{2} \mathbf{~ h}$ which had a higher inherent viscosity of $0.70 \mathrm{dL} \mathrm{g}^{-1}$. The structures of the polyarylates were confirmed by IR spectroscopy and elemental analysis. The sharp absorption peaks at around $1740 \mathrm{~cm}^{-1}(\mathrm{C}=\mathrm{O})$ and $1260 \mathrm{~cm}^{-1}(\mathrm{C}-\mathrm{O})$ are a clear indication of the esterforming reaction. The characteristic absorptions due to the asymmetric and symmetric $\mathrm{S}(=\mathrm{O})_{2}$ stretching of the sulfonyl groups appeared at around 1315 and 1160 $\mathrm{cm}^{-1}$, respectively. Elemental analysis values were also in good agreement with those calculated.

\section{Polymer Properties}

The solubility of these polyarylates was determined qualitatively in various solvents, and the results are summarized in Table II. The polyarylates such as $\mathbf{2 a , 2 f}$, $\mathbf{3 a}$, and $\mathbf{4 a}$ that precipitated in the polycondensation reaction reveal poor solubility; they are insoluble in most of the solvents tested. The other polyarylates show good solubility in various organic solvents, particularly in chlorinated hydrocarbons and phenols. In general, the ether-containing sulfonyl polyarylates have an improved solubility when compared to their analogs without ether linkages. However, it is worth noting that the methylsubstituted poly(ether-sulfone-arylate)s $\mathbf{4 b}-\mathbf{4 i}$ are readily soluble in THF, but insoluble in DMSO.
The crystallinity of the polyarylates was evaluated by wide-angle X-Ray diffraction analysis. The X-Ray diffraction patterns of all polyarylates are shown in Figure 1. Polyarylates $\mathbf{2 a}, \mathbf{2 f}$, and $\mathbf{3 a}$ showed stronger reflection peaks between $2 \theta=10$ to $20^{\circ}$, indicative of moderate to high degree of crystallinity. This corresponds to their poor solubility. The other polyarylates exhibited almost amorphous patterns. The amorphous nature of these polyarylates is generally consistent with their high solubility and outstanding film forming properties.

Transparent and flexible films of the soluble polyarylates could be obtained by casting from their TCE solutions. These films were subjected to tensile testing, and their tensile properties are summarized in Table III. They had tensile strengths of $49-76 \mathrm{MPa}$, elongations to break of $6-48 \%$, and tensile moduli of $1.39-1.86 \mathrm{GPa}$. Most of them behaved as strong and rigid materials. Only the film of polyarylate $\mathbf{2} \mathbf{b}$ behaved as a tough material. It necked during the tensile test and showed a relatively higher extension to break.

DSC, TMA, and TGA evaluated the thermal behavior of the polyarylates. The thermal data are summarized in Table IV. In the DSC experiments, the samples were first heated from 40 to $400^{\circ} \mathrm{C}$ with a heating rate of $20^{\circ} \mathrm{C}$ $\min ^{-1}$ and rapidly cooled to $40^{\circ} \mathrm{C}$ at $-200^{\circ} \mathrm{C} \min ^{-1}$, followed by a second heating run from 40 to $400^{\circ} \mathrm{C}$ at $20^{\circ} \mathrm{C}$ $\min ^{-1}$. The glass transition temperature $\left(T_{\mathrm{g}}\right)$ was defined as the midpoint of baseline shift on the second DSC heating trace. DSC observed no discernible $T_{\mathrm{gs}}$ for 
Table II. Solubility behavior of sulfonyl polyarylates ${ }^{a}$

\begin{tabular}{|c|c|c|c|c|c|c|c|c|}
\hline \multirow[b]{2}{*}{ Polymer } & \multicolumn{8}{|c|}{ Solvent $^{\mathrm{b}}$} \\
\hline & NMP & $\mathrm{THF}$ & DMSO & Chloroform & TCE & $o-\mathrm{CP}$ & $o-\mathrm{DCB}$ & $\begin{array}{c}\text { TCE/phenol } \\
(40 / 60)\end{array}$ \\
\hline $\mathbf{2 a}$ & - & - & - & - & - & - & - & - \\
\hline $\mathbf{2 b}$ & + & - & - & + & + & $+\mathrm{h}$ & - & + \\
\hline $2 c$ & + & - & + & + & + & + & - & + \\
\hline $\mathbf{2 d}$ & + & + & $+\mathrm{h}$ & $+\mathrm{h}$ & $+\mathrm{h}$ & + & + & + \\
\hline $2 \mathbf{e}$ & + & - & + & + & + & + & - & + \\
\hline $2 \mathrm{~g}$ & + & - & + & + & + & + & + & + \\
\hline $2 \mathbf{h}$ & + & + & - & + & $+\mathrm{h}$ & + & + & + \\
\hline $\mathbf{2 i}$ & + & + & $+\mathrm{h}$ & + & $+\mathrm{h}$ & + & - & + \\
\hline $\mathbf{3 a}$ & + & - & - & - & - & - & - & + \\
\hline $\mathbf{3 b}$ & + & - & + & + & + & + & + & + \\
\hline $3 c$ & + & - & + & + & + & - & + & + \\
\hline 3d & + & + & $+\mathrm{h}$ & + & + & + & + & + \\
\hline $3 \mathbf{e}$ & + & - & + & + & + & + & - & + \\
\hline $3 \mathbf{g}$ & + & + & + & + & + & + & + & + \\
\hline $\mathbf{3 h}$ & + & + & - & + & + & + & + & + \\
\hline $\mathbf{3 i}$ & + & + & + & + & + & + & + & + \\
\hline $4 a$ & - & - & - & - & - & + & - & + \\
\hline $4 b$ & + & + & - & + & + & + & + & + \\
\hline $4 c$ & + & + & - & + & + & + & + & + \\
\hline $\mathbf{4 d}$ & + & + & - & + & + & + & + & + \\
\hline $4 e$ & + & + & - & + & + & + & + & + \\
\hline 4f & + & + & - & + & + & + & + & + \\
\hline $4 \mathrm{~g}$ & + & + & - & + & $+\mathrm{h}$ & + & + & + \\
\hline $4 \mathrm{~h}$ & + & + & - & + & + & + & + & + \\
\hline $4 i$ & + & + & - & + & + & + & $+\mathrm{h}$ & + \\
\hline
\end{tabular}

${ }^{\mathrm{a}}$ Qualitative solubility tested with $10 \mathrm{mg}$ of sample in $1 \mathrm{~mL}$ of solvent. $+:$ soluble at room temperature; $+\mathrm{h}:$ soluble on heating at $100^{\circ} \mathrm{C}$; - : insoluble even on heating. ${ }^{\mathrm{b}}$ NMP: $N$-methyl-2-pyrrolidone; DMSO: dimethyl sulfoxide; THF: tetrahydrofuran; TCE: 1,1,2,2tetrachloroethane; $o$-CP: $o$-chlorophenol; $o$-DCB: $o$-dichlorobenzene.

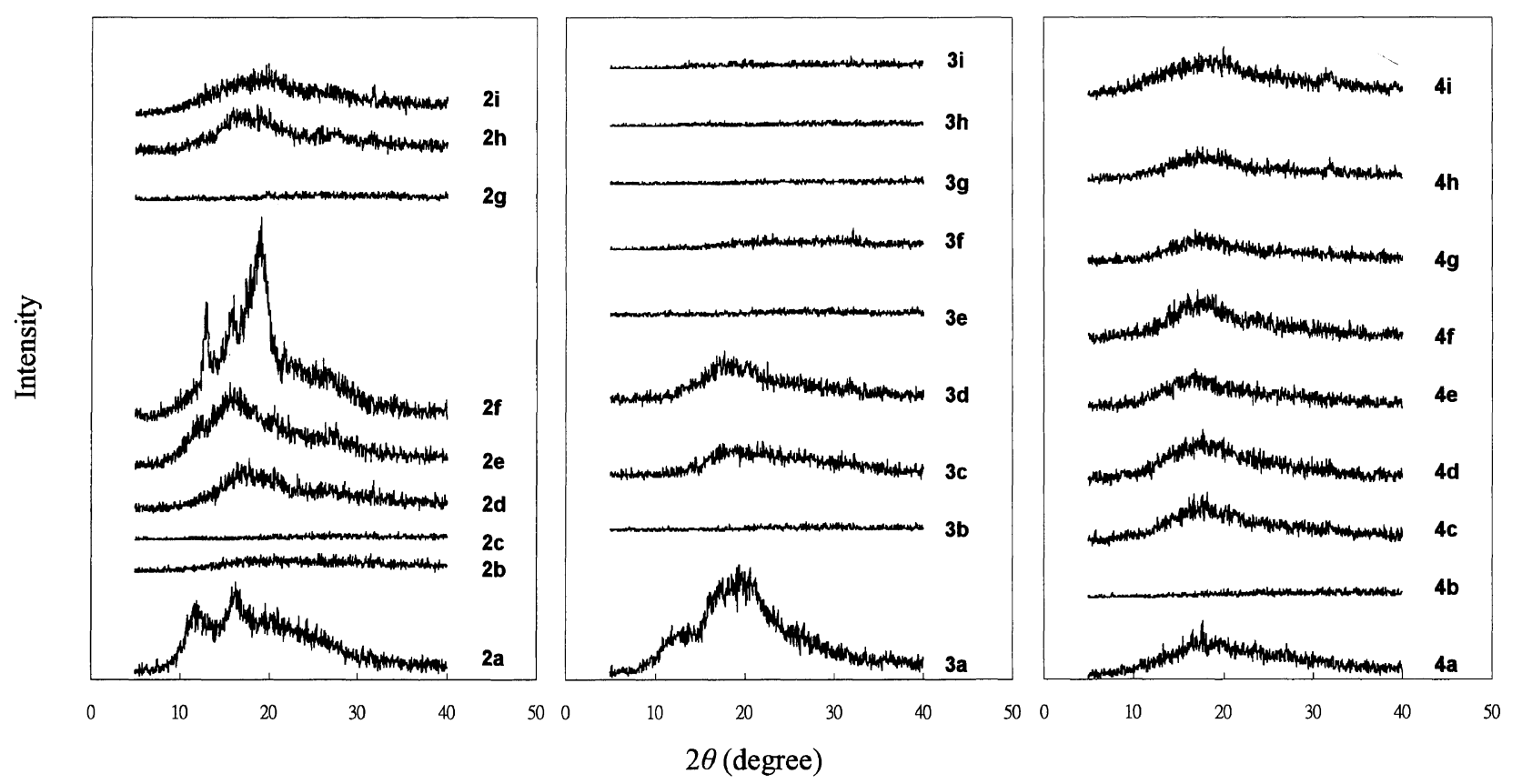

Figure 1. Wide-angle X-Ray diffraction patterns of the polyarylates.

polyarylates $\mathbf{2 a}, \mathbf{2 b}$, and $\mathbf{2 i}$. The other polyarylates revealed distinct glass transition on their second DSC heating traces. The first heating run of the aspolymerized sample of $2 \mathbf{f}$ (Figure 2) reveals a melting endotherm at $289^{\circ} \mathrm{C}\left(\Delta H=45 \mathrm{~J} \mathrm{~g}^{-1}\right)$. This result is consistent with that of X-Ray diffraction experiments and indicates that polymer $\mathbf{2 f}$ is semicrystalline in origin.
The $T_{\mathrm{g}} \mathrm{s}$ of polymers $3 \mathbf{a}-\mathbf{3 i}$ occur between 130 and $208^{\circ} \mathrm{C}$ and are lower than those of the corresponding polymer $\mathbf{2 a}-2 \mathbf{i}$. This result is reasonable in light of the increased chain flexibility imparted by the two bisaryloxy groups present in the $\mathbf{3 a - 3 i}$ polymers. As expected, the methylsubstituted poly(ether-sulfone-arylate)s $(\mathbf{4 a}-\mathbf{4 i})$ exhibited higher $T_{\mathrm{gs}}\left(194-283^{\circ} \mathrm{C}\right)$ as compared to the corre- 


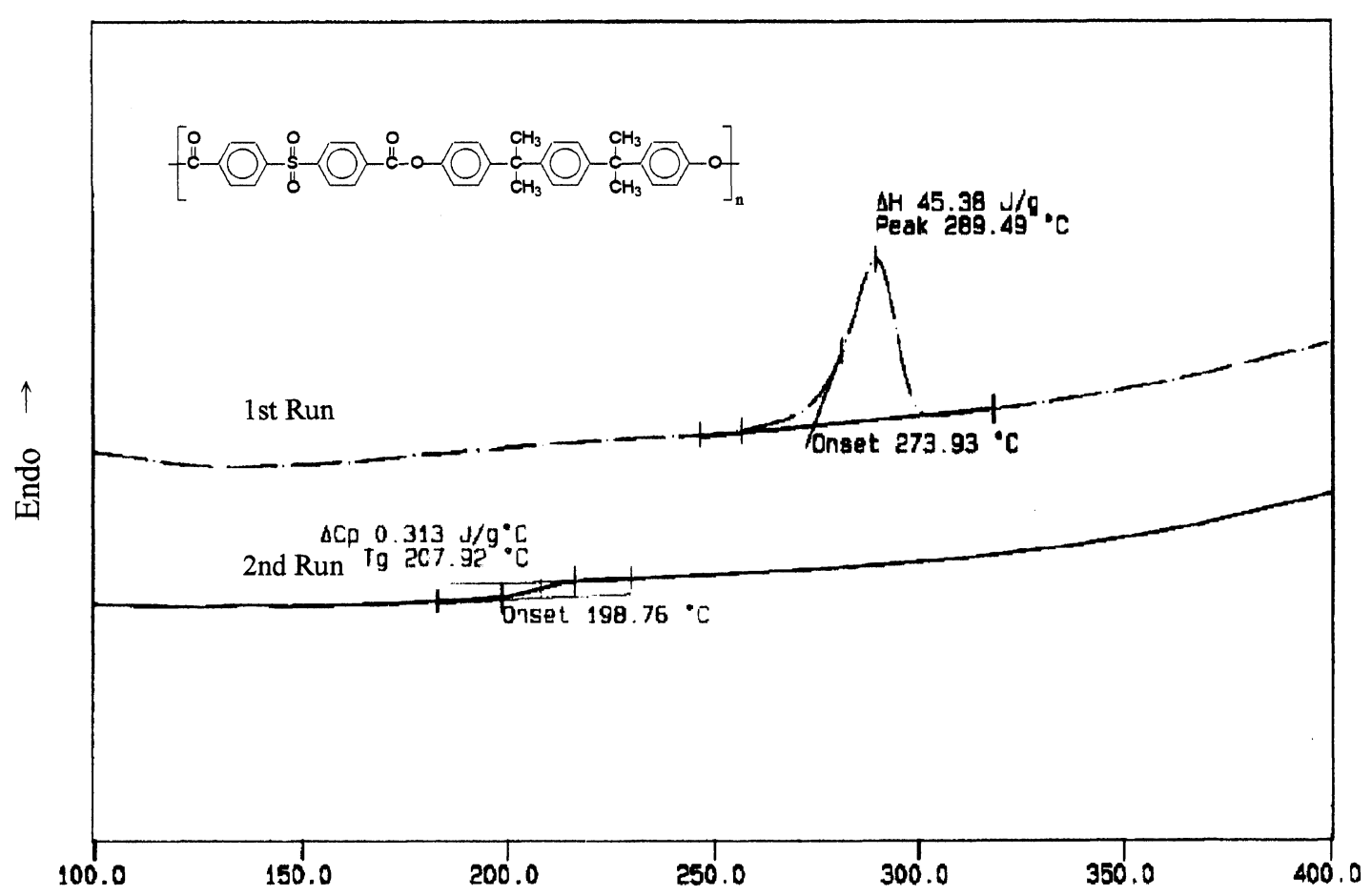

Figure 2. DSC curves of polyarylate $2 \mathrm{f}$ at a heating rate of $20^{\circ} \mathrm{C} \min ^{-1}$ in nitrogen.

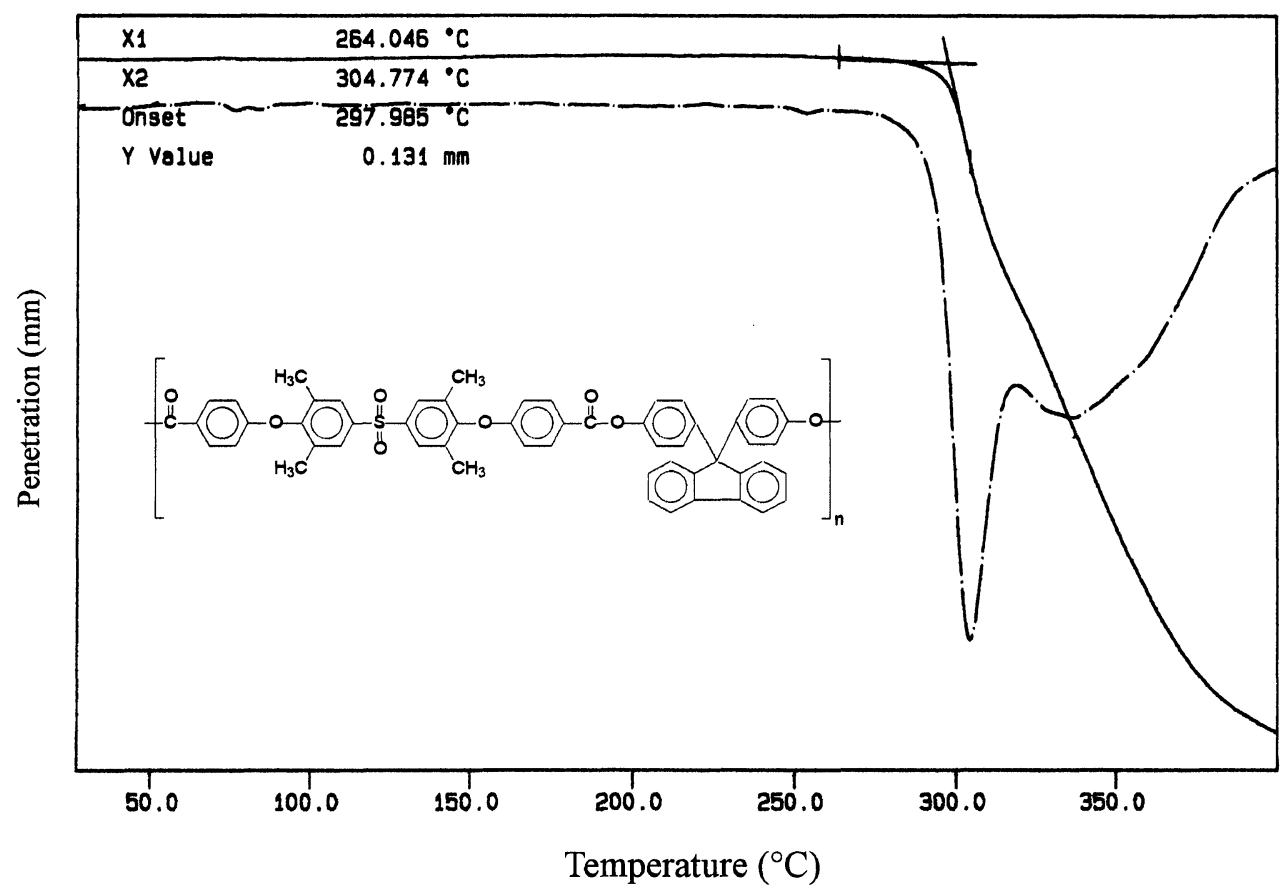

Figure 3. The TMA curves of polyarylate $4 \mathbf{i}$, conducted with a penetration probe of $1.0 \mathrm{~mm}$ diameter and using an applied constant load of $10 \mathrm{mN}$ at a heating rate of $10^{\circ} \mathrm{C} \mathrm{min}-1$.

sponding unsubstituted poly(ether-sulfone-arylate)s (3a -3i) due to the hindrance effect of the chain rotation in the methyl-substituted polymers. ${ }^{17}$ The $T_{\mathrm{g}} \mathrm{s}$ of the polyarylates are also highly dependent on the bisphenol component structures. The bisphenols 1 f and 1g-derived polyarylates containing flexible phenylenediisopropylidene structure generally revealed lower $T_{\mathrm{g}} \mathrm{s}$. On the other hand, the polyarylates obtained from bulky, rigid bisphenols such as $\mathbf{1 h}$ and $\mathbf{1 i}$ exhibited relatively higher
$T_{\mathrm{g}} \mathrm{s}$. In the case of polyarylates that give flexible films by solution casting, softening temperatures $\left(T_{\mathrm{s}}\right)$ were measured by TMA using a penetration method. A typical TMA curve for the representative polyarylate $4 \mathbf{i}$ is illustrated in Figure 3 . The $T_{\mathrm{s}}$ value was read as the intersection of the extrapolation of the baseline with the extrapolation of inflection on the TMA curve. In most cases, the $T_{\mathrm{s}}$ values measured by TMA are comparable to the $T_{\mathrm{g}}$ values determined by DSC. 
Table III. Tensile properties of polyarylate films ${ }^{a}$

\begin{tabular}{|c|c|c|c|c|}
\hline \multirow{2}{*}{ Polymer } & \multirow{2}{*}{$\frac{\text { Yield strength }}{\mathrm{MPa}}$} & \multirow{2}{*}{$\begin{array}{c}\begin{array}{c}\text { Strength to } \\
\text { break }\end{array} \\
\mathrm{MPa}\end{array}$} & \multirow{2}{*}{$\begin{array}{c}\begin{array}{c}\text { Elongation to } \\
\text { break }\end{array} \\
\%\end{array}$} & \multirow{2}{*}{$\begin{array}{c}\begin{array}{c}\text { Initial } \\
\text { modulus }\end{array} \\
\mathrm{GPa}\end{array}$} \\
\hline & & & & \\
\hline $2 b$ & 69 & 69 & 48 & 1.63 \\
\hline $2 c$ & 64 & 61 & 11 & 1.42 \\
\hline $2 d$ & 66 & 61 & 12 & 1.39 \\
\hline $2 f$ & 49 & 49 & 6 & 1.62 \\
\hline $2 h$ & 67 & 65 & 10 & 1.40 \\
\hline $\mathbf{2 i}$ & 69 & 68 & 12 & 1.39 \\
\hline $\mathbf{3 b}$ & 68 & 67 & 8 & 1.86 \\
\hline $3 c$ & 73 & 73 & 6 & 1.84 \\
\hline 3d & 71 & 71 & 7 & 1.65 \\
\hline 3f & 70 & 69 & 7 & 1.66 \\
\hline $3 \mathbf{g}$ & 72 & 67 & 10 & 1.64 \\
\hline $3 \mathbf{h}$ & 71 & 71 & 7 & 1.51 \\
\hline $\mathbf{3 i}$ & 76 & 76 & 7 & 1.64 \\
\hline $4 b$ & 76 & 76 & 6 & 1.82 \\
\hline $4 c$ & 69 & 68 & 8 & 1.52 \\
\hline $4 d$ & 67 & 63 & 11 & 1.51 \\
\hline $4 e$ & 65 & 60 & 11 & 1.41 \\
\hline 4f & 72 & 64 & 10 & 1.47 \\
\hline $4 \mathrm{~g}$ & 63 & 63 & 6 & 1.49 \\
\hline $4 \mathrm{~h}$ & 66 & 60 & 13 & 1.48 \\
\hline $4 i$ & 70 & 68 & 10 & 1.53 \\
\hline
\end{tabular}

${ }^{a}$ Films were cast from slow evaporation of polymer solutions in 1,1,2,2-tetrachloroethane. The cast films were dried under vacuum at $150^{\circ} \mathrm{C}$ for $6 \mathrm{~h}$ prior to the tensile test.

Table IV. Thermal behavior data of sulfonyl polyarylates

\begin{tabular}{|c|c|c|c|c|c|}
\hline \multirow{2}{*}{ Polymer } & \multirow{2}{*}{$T_{\mathrm{g}}{ }^{\mathrm{a}} /{ }^{\circ} \mathrm{C}$} & \multirow{2}{*}{$T_{\mathrm{s}}^{\mathrm{b}} /{ }^{\circ} \mathrm{C}$} & \multicolumn{2}{|c|}{$T_{\mathrm{d}}^{\mathrm{c}} /{ }^{\circ} \mathrm{C}$} & \multirow{2}{*}{$\frac{\text { Char yield }^{\mathrm{d}}}{\%}$} \\
\hline & & & $\operatorname{In} \mathbf{N}_{2}$ & In air & \\
\hline $\mathbf{2 a}$ & $-^{e}$ & - & 469 & 456 & 36 \\
\hline $\mathbf{2 b}$ & - & 285 & 445 & 436 & 58 \\
\hline $2 c$ & 253 & 245 & 478 & 462 & 32 \\
\hline $2 d$ & 268 & 263 & 474 & 467 & 34 \\
\hline $\mathbf{2 e}$ & 253 & 250 & 491 & 479 & 51 \\
\hline $2 f$ & $208(289)^{f}$ & - & 487 & 464 & 29 \\
\hline $2 \mathrm{~g}$ & 150 & 161 & 488 & 471 & 29 \\
\hline $\mathbf{2 h}$ & 287 & 287 & 456 & 437 & 35 \\
\hline $\mathbf{2 i}$ & - & 319 & 485 & 483 & 56 \\
\hline $\mathbf{3 a}$ & 186 & - & 478 & 432 & 42 \\
\hline $\mathbf{3 b}$ & 219 & 217 & 455 & 462 & 53 \\
\hline $3 \mathbf{c}$ & 169 & 178 & 489 & 473 & 36 \\
\hline 3d & 193 & 192 & 474 & 446 & 40 \\
\hline $\mathbf{3 e}$ & 184 & 187 & 499 & 486 & 54 \\
\hline 3f & 130 & 140 & 470 & 463 & 40 \\
\hline $\mathbf{3 g}$ & 135 & 152 & 490 & 464 & 31 \\
\hline $\mathbf{3 h}$ & 208 & 209 & 461 & 444 & 38 \\
\hline $\mathbf{3 i}$ & 197 & 201 & 470 & 480 & 56 \\
\hline $4 \mathbf{a}$ & 246 & - & 418 & 435 & 51 \\
\hline $4 \mathbf{b}$ & 234 & 237 & 411 & 435 & 54 \\
\hline $4 c$ & 238 & 243 & 415 & 429 & 43 \\
\hline $4 d$ & 245 & 245 & 419 & 432 & 50 \\
\hline $4 e$ & 240 & 247 & 415 & 427 & 50 \\
\hline 4f & 229 & 220 & 421 & 427 & 39 \\
\hline $4 \mathrm{~g}$ & 194 & 194 & 417 & 428 & 41 \\
\hline $4 h$ & 283 & 268 & 433 & 426 & 38 \\
\hline $4 \mathbf{i}$ & 279 & 298 & 428 & 440 & 60 \\
\hline
\end{tabular}

${ }^{a}$ The samples were heated from $40^{\circ} \mathrm{C}$ to $400^{\circ} \mathrm{C}$ with a heating rate of $20^{\circ} \mathrm{C} \mathrm{min}^{-1}$ and rapidly cooled to $40^{\circ} \mathrm{C}$ at $-200^{\circ} \mathrm{C} \min ^{-1}$. The midpoint of baseline shift on the subsequent second DSC heating trace was defined as $T_{\mathrm{g}}$. ${ }^{\mathrm{b}}$ Softening temperatures measured by TMA (penetration method) at a heating rate of $10^{\circ} \mathrm{C} \mathrm{min}-1$. ${ }^{\mathrm{c}}$ Decomposition temperatures at which $10 \%$ weight loss was recorded by TGA at a heating rate of $20^{\circ} \mathrm{C} \mathrm{min}{ }^{-1}$. ${ }^{d}$ Residual weight $(\%)$ at $600^{\circ} \mathrm{C}$ in nitrogen. ${ }^{\mathrm{e}}$ No discernible transition was observed. ${ }^{f}$ The endotherm peak temperature observed on the first heating DSC trace.

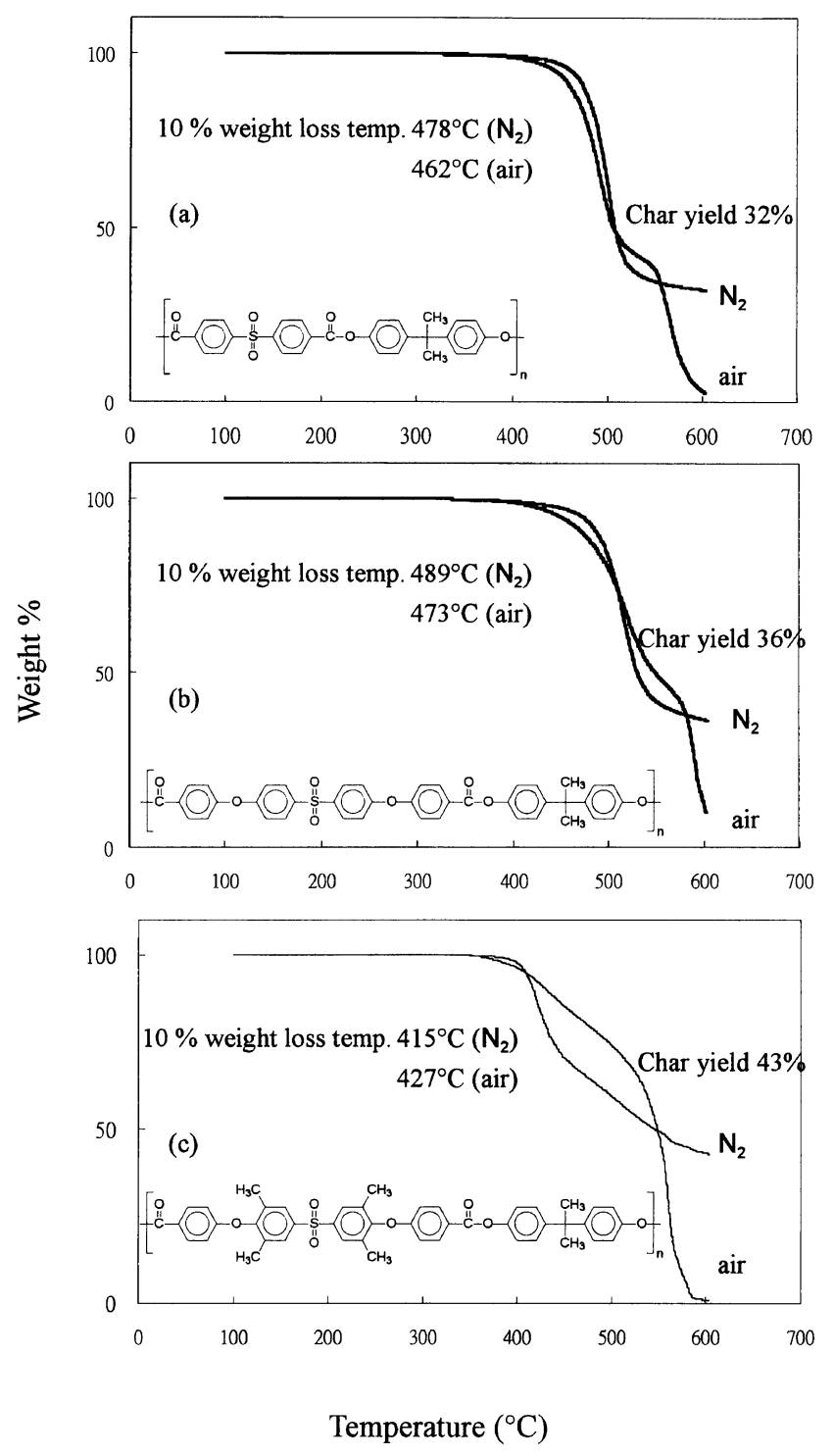

Figure 4. TGA curves of polyarylates (a) 2c, (b) 3c, and (c) 4c with a heating rate of $20^{\circ} \mathrm{C} \mathrm{min}-1$.

Dynamic TGA indicates that all the polyarylates have good thermal and thermo-oxidative stability due to no significant weight losses were observed up to $400^{\circ} \mathrm{C}$ in air or nitrogen atmosphere. Typical TGA thermograms of polyarylates $\mathbf{2 c}, \mathbf{3 c}$, and $\mathbf{4 c}$ are shown in Figure 4 . It is quite reasonable that the methyl-substituted polyarylate 4c began to decompose at lower temperatures compared with the unsubstituted polymers $\mathbf{2 c}$ and 3c. The TGA data of all polyarylates are also summarized in Table IV. Decomposition temperatures $\left(T_{\mathrm{d}}\right)$ corresponding to a $10 \%$ weight loss were recorded in the range of $426-486^{\circ} \mathrm{C}$ in air and $411-499^{\circ} \mathrm{C}$ in nitrogen, with $29-60 \%$ char residue remaining at $600^{\circ} \mathrm{C}$ in nitrogen.

\section{CONCLUSIONS}

A series of polyarylates having the sulfone group or both of the ether and sulfone groups were successfully synthesized by means of the interfacial polycondensation of the sulfonyl diacid chlorides SDBC, SODBC, and 
4MeSODBC with various bisphenols. Most of the polyarylates have moderate to high molecular weights and form strong, transparent, and colorless films. Depending on the structures of the diacid chloride and bisphenol moieties, the $T_{\mathrm{g}}$ or $T_{\mathrm{s}}$ values of the polyarylates can be controlled in a wide range of 130 $319^{\circ} \mathrm{C}$. The introduction of ether groups in the polymer main chain led to a decreased $T_{\mathrm{g}}$ and $T_{\mathrm{s}}$. Methyl substitution resulted in an enhanced $T_{\mathrm{g}}$ and $T_{\mathrm{s}}$, but a lower initial decomposition temperature. Good solubility, moderate $T_{\mathrm{g}}$ and $T_{\mathrm{s}}$ values suitable for molding, and reasonable thermal stability make these sulfonyl polyarylates promising high performance engineering plastics or polymeric membranes.

Acknowledgment. The authors thank National Science Council for financial support which enabled this work to be undertaken.

\section{REFERENCES}

1. L. M. Robeson and J. M. Tibbitt, 'History of Polyarylates', in "High Performance Polymers: Their Origin and Developments", R. B. Seymour and G. S. Krishenbaum, Ed., Elsevier, Amsterdam, 1986, pp 95-103.

2. V. V. Korshak and S. V. Vinogradov, Polyesters, Pergamon
Press Ltd., New York, N.Y., 1965.

3. S.-H. Hsiao and P.-C. Huang, Macromol. Chem. Phys., 198, 4001 (1997).

4. S.-H. Hsiao and P.-C. Huang, J. Polym. Sci., Part A: Polym. Chem., 35, 2421 (1997).

5. S.-H. Hsiao and P.-C. Huang, J. Polym. Sci., Part A: Polym. Chem., 36, 1649 (1998).

6. S.-H. Hsiao, C.-P. Yang, and T.-K. Lo, J. Polym. Res., 5, 193 (1998).

7. S.-H. Hsiao, C.-P. Yang, and C.-T. Li, J. Polym. Res., 5, 243 (1998).

8. H. Manami, M. Nakazawa, Y. Oishi, M. Kakimoto, and Y. Imai, J. Polym. Sci., Part A: Polym. Chem., 28, 465 (1990).

9. C. Chiriac and J. K. Stille, Macromolecules, 10, 712 (1977)

10. S. B. Idage, B. B. Idage, B. M. Shinde, and S. P. Vernekar, $J$. Polym. Sci., Part A: Polym. Chem., 27, 583 (1989).

11. W. M. Eareckson, J. Polym. Sci., 40, 399 (1959).

12. P. W. Morgan and S. L. Kwolek, J. Polym. Sci., 40, 299 (1959).

13. P. W. Morgan, "Condensation Polymers by Interfacial and Solution Methods", Interscience, New York, N.Y., 1965.

14. Y. Imai and S. Tassavori, J. Polym. Sci., Polym. Chem. Ed., 22, 1319 (1984).

15. C.-P. Yang and S.-H. Hsiao, J. Polym. Sci., Part A: Polym. Chem., 28, 871 (1990).

16. S.-H. Hsiao and H.-Y. Chang, J. Polym. Res., 2, 99 (1995).

17. F. Keitoku, M. Kakimoto, and Y. Iami, J. Polym. Sci., Part A: Polym. Chem., 32, 317 (1994). 